\section{Opioids and chronic pain}

The $C M A J$ editorial about opioids and chronic pain, "Better management of chronic pain care for all," "myths about addiction" and states that the potential for addiction is "frequently exaggerated."

The risk of opioid addiction in prescribing opioids for chronic pain is quantifiable ${ }^{2}$ and, in some cases, predictable. ${ }^{3}$ The Canadian Guideline for Safe and Effective Use of Opioids for Chronic Non-Cancer Pain ${ }^{4}$ recommends documentation of substance use history in a comprehensive assessment before prescribing opioids. A previous or current substance-use disorder increases the risk of opioid addiction upon exposure to the class of drug. If the choice is made to proceed with opioid treatment in such a case, additional monitoring can be put in place, and patients can be advised of the risk to ensure fully informed consent. Patients at very high risk can be advised that, if opioid therapy fails or if addiction behaviours emerge, methadone or buprenorphine maintenance treatment may become the only safe treatment choice.

The concept of universal precautions in pain medicine ${ }^{5}$ asserts that a minimum level of vigilance be applied to all patients who are prescribed opioids. Similar to infectious disease, opioid addiction may emerge in seemingly low-risk patients. Following universal recommendations in pain management and opioid prescribing, including risk assessment and monitoring addiction, creates the effect of containing the level of risk for all.

The argument could be made that, short of death due to intentional or unintentional opioid overdose, opioid addiction is the most significant adverse effect of long-term opioid therapy for chronic pain. Physicians who prescribe opioids for patients with chronic pain, especially to higher-risk patients, should be prepared to recognize and manage aberrant drug-related behaviours and opioid addiction. Management can include structured opioid therapy, ${ }^{6}$ referral for opioid maintenance with methadone or buprenorphine, or abstinence-based treatment. When opioid addiction is identified and treated appropriately, patients do very well and quality of life is restored.

Untreated addiction is a devastating illness, affecting all aspects of a patient's functioning, and is sometimes fatal. We cannot dismiss this illness in considering whether to proceed with opioid therapy. The constructive route, as with managing adverse effects from any other class of drugs, is to be well equipped to recognize and manage a serious adverse effect should it arise.

\section{Lisa Bromley MD}

Physician, Sandy Hill Community Health Centre, Ottawa, Ont.

\section{References}

1. MacDonald NE, Flegel K, Hébert PC. Better management of chronic pain care for all [editorial]. CMAJ 2011; 183:1815.

2. Fishbain DA, Cole B, Lewis J, et al. What percentage of chronic nonmalignant pain patients exposed to chronic opioid analgesic therapy develop abuse/addiction and/or aberrant drug-related behaviors? A structured evidence-based review. Pain Med 2008;9:444-59.

3. Webster LR, Webster RM. Predicting aberrant behaviors in opioid-treated patients: preliminary validation of the Opioid Risk Tool. Pain Med 2005;6:432-42.

4. The Canadian guideline for the safe and effective use of opioids for chronic non-cancer pain 2010. Hamilton (ON): National Opioid Use Guideline Group; 2010. Available: http://nationalpaincentre .mcmaster.ca/ (accessed 2011 Sept. 2).

5. Gourlay DL, Heit HA, Almahrezi A. Universal precautions in pain medicine: a rational approach to the treatment of chronic pain. Pain Med 2005;6: 107-12.

6. The Canadian guideline for the safe and effective use of opioids for chronic non-cancer pain 2010: Cluster $5, R 21$. Hamilton $(\mathrm{ON})$ : National Opioid Use Guideline Group; 2010. Available: http://national paincentre.mcmaster.ca/ (accessed 2011 Sept. 2).

CMAJ 2012. DOI:10.1503/cmaj.112-2001

MacDonald and colleagues ${ }^{1}$ rightly identify the need to scale up clinics for treatment of chronic pain and improve the availability of quality care for pain to Canadians in need. The proposed approach provides a rough framework to improve Canadians' access to relief from pain. In the global context, however, the undertreatment of pain remains a health tragedy, ${ }^{2}$ and improving access to even basic treatment is far less straightforward than scaling up existing services.
Morphine - one of the most basic analgesics for treating moderate-tosevere pain - is almost wholly unavailable in many parts of the world, despite being listed as an essential medicine by the World Health Organization. $^{3}$ The underlying rationale for this is complex and varies among nations, but has its origins in international treaties that have a dual mandate of ensuring access while simultaneously curtailing diversion from licit to illicit markets. ${ }^{4}$ Overwhelmingly, the emphasis has been placed on prohibition rather than access, resulting in over $80 \%$ of the world's population having no functional access to controlled narcotics. ${ }^{5}$

Improving the management of both acute and chronic pain care in the global context necessitates more than scaling-up services. Rather, it requires a paradigm shift in the way controlled narcotics are viewed, so as to prioritize access for medical purposes rather than the prohibition of illicit narcotics. Education of health professionals must follow suit; however, first we must ensure that basic supplies are made legally accessible to patients and providers.

\section{Jason W. Nickerson}

PhD Candidate, Centre for Global Health, Institute of Population Health, University of Ottawa

\section{Amir Attaran BA MS DPhil LLB}

Associate Professor, Faculties of Law and Medicine, University of Ottawa, Ottawa, Ont.

\section{References}

1. MacDonald NE, Flegel K, Hébert PC. Better management of chronic pain care for all [editorial] CMAJ 2011;183:1815

2. Liberman J, O'Brien M, Hall W, et al. Ending inequities in access to effective pain relief? Lancet 2010;376:856-7

3. World Health Organization. WHO model list of essential medicines - 17th list. Geneva (Switzerland): The Organization; 2011. Available: http://wh libdoc.who.int/hq/2011/a95053_eng.pdf (accessed 2011 Aug. 15).

4. United Nations. Single convention on narcotic drugs, 1961. United Nations; 1961. Available: www .unodc.org/pdf/convention_1961_en.pdf (accessed 2011 June 2).

5. Scholten W, Nygren-Krug H, Zucker HA. The World Health Organization paves the way for action to free people from the shackles of pain. Anesth Analg 2007;105:1-4.

CMAJ 2012. DOI:10.1503/cmaj.112-2002 